\title{
The Zika Outbreak- Possible Neurological Consequences of Infection
}

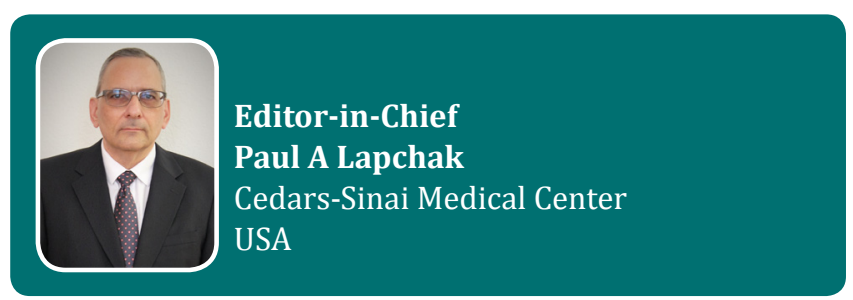

\section{Welcome to this Issue of the Journal of Neurology and Neurophysiology, a Translational Research Journal}

The Zika virus has been a headline focus for in the news for many months, and is the focal point of a new review article entitled "Zika Virus: The new rubella epidemic" by Dr. Kerrie Nguyen and colleagues [1]. Zika is a flavivirus spreading worldwide and becoming a public health emergency and epidemic due to transmission of the virus by the bite of the infected Aedes species mosquito vector, either Ae. aegypti, commonly known as the yellow fever mosquito (left photo panel) and Ae. albopictus also known as (Stegomyia albopicta), or the (Asian) tiger mosquito (right photo panel) (Figure 1).

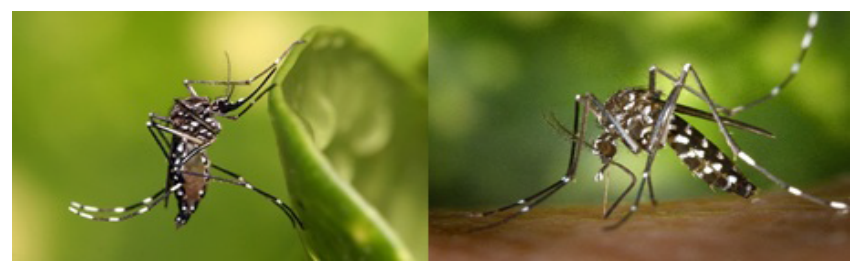

Figure 1: [Photograph credits Muhammad Mahdi Karim for Ae. aegypti [2] (PHIL) and Centers for Disease Control and Prevention's Public Health Image Library (PHIL), with identification number \#2165 for Ae. Albopictus [3].

Dr. Nguyen states that "there have been 11,528 laboratoryconfirmed cases of Zika in the US and territories" as of August 2016. Accurate diagnosis to confirm Zika utilizes real-time-reversetranscriptase polymerase chain reaction (rRT-PCR) and "can use body fluids such as serum, urine, CSF, amniotic fluid or semen". There are no current Zika-specific treatments, but vaccines are being pursued.

There are two main devastating outcomes of Zika virus infection: Microcephaly and Guillain-Barré syndrome

- Zika virus infection during pregnancy is a cause of microcephaly, a medical condition in which the circumference of the head is smaller than normal because the brain has not developed properly or has stopped growing. Microcephaly can be present at birth or it may develop in the first few years of life. It is most often caused by genetic abnormalities that interfere with the growth of the cerebral cortex during the early months of fetal development. Microcephaly is associated with Down's syndrome, chromosomal syndromes, and neurometabolic syndromes. With viral-induced brain injury, such as with the Zika virus, there is often widespread tissue and cell death leading to brain shrinkage rather than simply impaired growth. The Zika virus is also associated with retinal lesions in about a third of cases, often leading to blindness. Depending on the severity of the accompanying syndrome, children with microcephaly may have impaired cognitive development, delayed motor functions and speech, facial distortions, dwarfism or short stature, hyperactivity, seizures, difficulties with coordination and balance, and other brain or neurological abnormalities [4].

- Guillain-Barré syndrome (GBS) is a rare disorder in which the body's immune system attacks part of the peripheral nervous system (PNS). GBS is characterized by PNS demyelination. The first symptoms of this disorder include varying degrees of weakness or tingling sensations in the legs. In many instances, the weakness and abnormal sensations spread to the arms and upper body. These symptoms can increase in intensity until the muscles cannot be used at all and the person is almost totally paralyzed. In these cases, the disorder is life-threatening and is considered a medical emergency. The individual is often put on a ventilator to assist with breathing. Most individuals, however, have good recovery from even the most severe cases of GBS, although some continue to have some degree of weakness (Reference: Public Domain Information from National Institutes of Health, National Institute of Neurological Disorders and Stroke [5].

All Journal of Neurology and Neurophysiology readers should refer to either the CDC website for constant updates on the spread of the Zika virus or WHO International website [6,7].

To that end, I invite your dedicated attention to reading the Zika review article in this issue of the Journal of Neurology and Neurophysiology.

- Moreover, in this issue are important clinical studies relating to the deleterious effects of extended cell phone use on hearing measured using Brainstem Evoked Response Audiometry (BERA). The article suggests that cell phone electromagnetic radiation causes the damage.

*Corresponding author: Paul A Lapchak, Department of Neurology and Neurosurgery, Cedars-Sinai Medical Center, 127 S. San Vicente Blvd. AHSP, Suite 8305, Los Angeles, CA 90048, USA, Tel: 310-248-8188; Fax: 310-248-7568; E-mail: Paul.Lapchak@cshs.org

Received August 25, 2016; Accepted August 26, 2016 ; Published August 28 2016

Citation: Lapchak PA (2016) The Zika Outbreak- Possible Neurological Consequences of Infection. J Neurol Neurophysiol 7: e119. doi:10.4172/21559562.1000e119

Copyright: (C) 2016 Lapchak PA. This is an open-access article distributed under the terms of the Creative Commons Attribution License, which permits unrestricted use, distribution, and reproduction in any medium, provided the original author and source are credited. 
- Advances in the treatment of Parkinson's disease are underscored in a mini-review on the develop profile of hypoestoxide. The authors review known mechanisms of action of the diterpene including the inhibition of $\alpha$-synuclein aggregation, which may be a viable target to slow the progression of the disease. An additional article details electrode placement procedures for deep brain stimulation (DBS) to produce optimal results in Parkinson's disease patients.

- Last, there are a series of clinical articles pertaining to Transcranial Magnetic Stimulation, and changes in autonomic nervous system after concussion, specifically impaired ability to shift from parasympathetic to sympathetic control over heart rate after a concussion.

The journal is being well received by the clinical and translational research community, and we sincerely thank all authors for their valuable scientific contribution to the journal. All articles undergo the peer review process by the editorial board and by international reviewers, and only the select articles that meet specific criteria are published in the open-access journal. I invite you to submit your own original scientific articles, review articles, case reports or commentaries for peer-review to be published in future issues of the journal.

\section{References}

1. Nguyen KK, O'Brien BE, Steele RW (2016) Zika Virus: The New Rubella Epidemic. J Neurol Neurophysiol 7: 390.

2. Photograph credits Muhammad Mahdi Karim for Ae. aegypti

3. Centers for Disease Control and Prevention's Public Health Image Library (PHIL), with identification number \#2165 for Ae. albopictus

4. Public Domain Information from National Institutes of Health, National Institute of Neurological Disorders and Stroke.

5. Public Domain Information from National Institutes of Health, National Institute of Neurological Disorders and Stroke.

6. CDC website for constant updates on the spread of the Zika virus

7. WHO International website. 